\title{
PW01-031 - Treatment of FMF in middle and old age
}

\author{
A Ayvazyan \\ From 7th Congress of International Society of Systemic Auto-Inflammatory Diseases (ISSAID) \\ Lausanne, Switerland. 22-26 May 2013
}

\section{Introduction}

Current recommendations for the treatment of familial Mediterranean fever (FMF) are based largely on the observation of FMF patients receiving colchicine therapy in childhood and young age. The adequate colchicine therapy led to more and more patients survive to that age. In addition, there are national peculiarities of FMF. For example, in Armenia, even before the massive use of colchicine therapy, many patients survived to middle and old age.

\section{Objectives}

We have investigated the corse of FMF in middle and old age, the incidence of miocardial infarction and the outcomes in case of myocardial infarction.

\section{Methods}

Follow-up during 10-30 years.

\section{Results}

Our research has shown that the risk of amyloidosis decreases with age, and the ability of colchicine to prevent attacks of FMF increases with age. Our research has also shown that in the absence of regular colchicine therapy increases the risk of myocardial infarction. In addition, myocardial infarction in patients with FMF is more severe, with a higher risk of death. With age the incidence of many diseases is increased, but their co-therapy with colchicine has not been studied.

\section{Conclusion}

To date, may be recommended in middle and old age to take colchicine at a dosage that fully prevents the attacks of FMF in young age. If treatment is initiated in middle or old age, the dosage of colchicine should be higher

Yerevan State Medical University, Yerevan, Armenia than necessary to control the attacks of illness and indicators of inflammation. Untreated in young age FMF should be considered as a risk factor for CHD. Patients with FMF in the case of acute myocardial infarction should be observed over a long time and prevention of complications should be more intense. Urgently need to be initiated the multi-center and national studies on the combined treatment of FMF and the most common diseases in middle and old age.

\section{Disclosure of interest}

None declared.

Published: 8 November 2013

doi:10.1186/1546-0096-11-S1-A84

Cite this article as: Ayvazyan: PW01-031 - Treatment of FMF in middle and old age. Pediatric Rheumatology 2013 11(Suppl 1):A84.

Submit your next manuscript to BioMed Central and take full advantage of:

- Convenient online submission

- Thorough peer review

- No space constraints or color figure charges

- Immediate publication on acceptance

- Inclusion in PubMed, CAS, Scopus and Google Scholar

- Research which is freely available for redistribution (c) 2013 Ayvazyan; licensee BioMed Central Ltd. This is an Open Access article distributed under the terms of the Creative Commons Attribution License (http://creativecommons.org/licenses/by/2.0), which permits unrestricted use, distribution, and reproduction in any medium, provided the original work is properly cited. 